\section{Three Incidents at the Border of Genre}

\section{Stian Grøgaard}

Oslo National Academy of the Arts

stian.s.grogaard@khio.no

\section{ABSTRACT}

From a perspective of conceptual economy, rather than the specialized literature on genre, this text discusses what genre divisions can do when applied to cultural artifacts compared to other forms of classification or typology. On which aspect of the artifact is it rewarding for a concept of genre to operate, and what is achieved when extending its use beyond traditional divisions in fine arts, Hollywood movies and popular music? Are there restrictions inherent to the concept of genre itself, explicable in a grammar of the concept? The criteria unfolded by such a grammar seems to be more technical than properly aesthetic, close to the ideal of perfection in traditional normative poetics. With one significant addition, the criteria are always too specific to allow for the perfect example of genre. Perfection belongs to the law of the genre, not to the artifact enforcing the law. Im-
The Journal of Media Innovations 3.2 (2016), 20-29.

DOI: http://dx.doi.org/10.5617/jmi.v3i2.2492

(c) Stian Grøgaard 2016 perfection may indeed explain the resilience of the genre form. What remains is a vertical structure, a model for which even the model example is a fall from grace.

\section{Keywords}

Applied aesthetics; Genre; Restrictive economy; Genre sublation; Art versus genre; Edvard Munch; Clint Eastwood; Bob Dylan.

\section{INTRODUCTION}

Everyone knows what genre is. The familiar concept promises easy access but is actually difficult to handle. Spotting the difficulty will have to begin with the constancy of genre and why it is taken for granted. Constancy provides a measure for new expressions and an order to which they can belong. Quite independent of genre theories, the concept of genre displays a certain structure and extension in short, a grammar. While a general outline of this grammar may be gained by conceptual analysis, the specifics must consult experience from, as always, a limited number of genres. These are two sources of information, one analytical and the other synthetical, and they had best not contradict each other.

The following general remarks do not comment upon the research literature on genre, with which I shall claim no close acquaintance. Based on a mix of ignorance and fastidiousness concerning genre, 
the point is to evoke limits to a concept. Less than generalizing from experience, it is about holding a concept up to the test of experience.

Laying out genre analytically and relying on a consumer's and sometimes a practitioner's experience with genre is an approach with no guarantees and may be taken as an admonition to the practice of genre theory. Any attempt to answer questions put to genre in general will have to move forward with the help of examples, in this case, early modernist painting, a Hollywood movie, and almost contemporary popular music. These examples include: a well-known motif belonging to genre painting in Edvard Munch's The Sick Child from 1886; a western, the quintessence of genre movies, for instance in an updated version like Unforgiven (1992) by Clint Eastwood; and the recycling of traditional music genres as in the case of Bob Dylan's 1982 homage to the songster and virtuoso twelvestring guitarist Blind Willie McTell. First, a few tentative remarks on genre in general.

Classifying art forms is different than classifying expressions that belong to each art form. Art is not subdivided into genres of art, or for that matter, genres of anything else. Genre division is internal to each form. This difference holds for media tech- nologies as well. Media are not considered genre, but there are genres that differentiate each medium. What is at issue here is a specificity initiated at the level of art practice itself that accounts for genre division, rather than genre presenting itself to each art form as a given condition. There is an end to genre's suitability in ordering the practice of art and the production of artifacts. Genre divisions extend beyond the arts, but there are limits to their application. This may be due to some sort of grammar inherent to the concept of genre, where the grammar is different than the immanent law of each genre. What then is the difference between forms of art and genres of art, and is there some similarity between genre divisions within each art form?

Genre is suited to classify music and its application can be extended to continuously new forms of expression. Since genre's classification is open, it cannot be applied normatively and in accordance with a vertical distribution of value. The same goes for art forms where genre markers may be more complex. In literature and film, according to the Store norske leksikon (1995), genre refers to both formal and thematic markers. Epic, drama and lyric are genres with each their own subgenres. For- mulas for proven success at the box office like musical, thriller, horror, action, film noir or western all pass under the umbrella of genre movies.

Earlier, traditional visual subjects were classified according to a genre hierarchy, where the term "genre painting" came to occupy the bottom scale. Genre painting shows "daily life in its typical commonness," and was a popular visual form from the mid $-18^{\text {th }}$ century onwards with common people absorbed in modest activities with no asides, that is, showing no awareness of the spectator. According to Michael Fried (1998), absorption was challenged in early modernist painting - Manet's Olympia (1863) being a notable example - but was again absorbed by the medium itself in the painterly abstraction of high modernism. Olympia presents a nude woman, or rather a woman wearing only her slippers, reclining on a bed. She looks out of the picture in the direction of the spectator, thereby bringing him (because it is preferably a male gaze) into the picture and thematizing the situation before the painting. Still, this threshold experience in modern art was based on a motif known to be popular already in the Renaissance, termed "the mistress portrait" by art historians - a famous and probably model example for Manet being Titian's 
Venus of Urbino from 1538. By the time of painterly abstraction in the beginning of the $20^{\text {th }}$ century, genre divisions had become non-scriptive and a non-starter.

\section{CONCEPTUAL ECONOMY}

There are functional limits to genre, which no extension will undo. Descriptive uses of genre promise a view from the outside, a pleasure so often invited by extended concepts.

Finding a common denominator for genre may extend these limits and miss the point of orthodoxy and exclusion, the normative view from within. Conversely, the multiplication of genres does not change their conceptual economy. There are silent conditions difficult to express even when comparing a host of genre neighbors. To encounter genre on the level of conceptual economy means observing how its order comes about, is extended, revised or eventually abandoned. Genre frames what Bataille would call a restricted economy, and any conceptual economy would of itself be restricted, that is, properly economical, to avoid the opposite risk of letting the concept go to waste. A general or unreserved economy, on the other hand, is uneconomi- cal, like burning crops or spending everything in a vast display of consumption rather than storing for future needs, and is thus geared towards extinction rather than accumulation. There are concepts close to a general economy, a free-for-all, which would lose themselves at their fringes and give their secrets away. Still, a sense of reserve or forlorn authority will cling to genre. Other typologies may be easier to let go to waste.

There is little doubt as to what is prior, the genre or the artifacts belonging to a genre. It only appears as if genre comes first, and this appearance is telling. New artifacts, if accepted as belonging to a genre, appear to be possibilities already in demand by the genre. When not accepted, nothing further happens because genre feeds on exclusion. There have been instances where the artifact carries genre markers but the exclusion ends up being mutual - genre excludes art and vice versa. A clean exit from genre was effected in modern art. Genre motifs like the nude, landscape or still life lived on simply as pretexts for painterly practice, the motifs themselves being insubstantial. At one point in history, fine art became uneasy with genre and, in fact, with any form of classification. All it needed was to be art, that is, art in general. Even "fine" before art was one qualification too many. In late modernism differences of discipline and the specific medium itself met with a similar fate and became vestiges of a superficial identification of what art was all about. At the same time, some allowance was made for modern media like photography or film: these are media still connected to ordinary communication but disclosing a more complex relationship to art than traditional media like painting, whose identity is exclusively tied to art. The difference between art film and genre film is not just commercial. The identification of a genre film as art signals the wrong social reasons for it being art. The identification of an art film as genre would likewise be deadly to its status as art.

From a perspective of conceptual economy, for instance, of a restricted versus a general economy mentioned above, art and its exit from genre is less interesting than cases of genre change or sublation of genre. The question is whether there is a conceptual economy in common for what is accepted, rejected, or for that which creates a new genre. Hegel describes this as the "immanent rhythm of concepts (1976, p. 56). Aufheben, or sublation in English, is the term used by Hegel to describe the dynamism of concepts if they can indeed be said to move at all. As with immanent rhythm, the sublation of a concept with another must be internal and necessary. 
Bataille's generation of the concept general economy was in fact aimed at the notion of sublation for not being general enough in its undisturbed accumulation of knowledge and never-failing memory. Perhaps subversion of genre would be more appropriate and the rhythm more fatal. For subversion there can be no second chance for the genre in point, while sublation promises a return to a more elevated form of the same. So, in defense of a restricted economy and with the blessing of Bataille, one may opt for sublation to describe the rhythm of a genre returning to lay claim on new forms.

\section{THE AUTHORIZED RECEIVER}

What then about the recipient of genre? Within unyielding norms, a particular sensitivity is optimized. This sensitivity is by no means the sole property of the producer of artifacts. In consumer culture, genre is handed over to the receiver and the customer. This reflects commercial concerns, which ensure that the customer is always right. But there is more to this than lip service. The consumer becomes an insider to genre, matching the knowledge of the producer as an authorized receiver. There is an asymmetry of investment in the artifact.
No matter the intent, the producer not only serves a customer but a connoisseur. Any consumer of genre soon learns exactly what fits and what does not. If this is a form of knowledge, then it will only accumulate on the opposite side of art. It involves a sense of limits as well as a sense of what resides within them. The development of an ear for differences that owe everything to the priority of genre, although resting on all but solid ground, suggests a proximity to taste as a form of sensus communis that under favourable circumstances becomes representative for everyone. The point is that the ear for genre does not expect anyone's approval, not even ideally. It remains positive no matter what common sense would contend.

It is not easy to tell what directs an ear tuned to genre when it judges an artifact a success or a failure, when it refuses the artifact for not complying to the norm, or when it even admits that the artifact is an improvement with the strange effect of historicizing its own standards. The apparent need to invent new genre for new media technology raises the question of how a genre originates. The next question is whether the need for invention ends up being met by simply transferring existing genre to a new medium. Traditional norms were specific and technical, inviting a transfer between media that somehow seems inadequate to a delicate ear for genre. In fact, invention involves living by the law of genre, presenting practice as technique, and is thus out of tune with the priority of genre.

Genre norms seem more technical than aesthetical, prolonging the ideal of perfection in traditional poetics. At the same time, these norms will never allow for the perfect case. Perfection resides with the genre, while the case remains in Benjamin Paul Blood's words "ever not quite," and it is precisely this imperfection that explains the genre's resilience. The perfect western remains to be made. Its aim for perfection is disclosed by its appetite for and dependence on clichés. Genre needs standard expressions as a framing device to optimize its performance, both in order to function commercially and to meet communicative expectations.

Of course we know this ideal perfection to be comparative, unearthed from exemplary cases. There can be no genre unless there are cases of genre, no western without westerns, which make genre an accumulation of markers taken from specific cases over time. The problem is that the law is already in place. What remains is a vertical structure, descriptive or not, a model for which even the model example is a fall from grace. This does not rule out a different order, where the example turns 
out to be exemplary of something else less restricted but also less transparent. This something other than genre may be closer to a definition of fine art when art became modern. Inside genre, the receiver is the one who is supposed to know, lending his or her voice to the exemplary expression. Modern art changed the relation to the receiver. Here the one supposed to know could be no other than the producer. The receiver had to be represented by the critic, who had to resort to interpretation, that is, a careful approximation of the things the producer knew.

\section{THE SICK CHILD}

The first example concerns genre in Edvard Munch's The Sick Child (1886), which has been hailed as the first modern painting in Norwegian art (see figure 1). Iconographically, it was a failed genre painting, which happened to break the laws of genre and thereby an unwritten social contract with the spectator. Retroactively, it became an emblem of its theme - a child dying from tuberculosis during the pandemic of the late 19th century. Underneath the emblem something strange took place, namely a displacement of what painting was supposed to do. This particular painting failed to document a memory trace and involuntarily succeeded in exposing a basic condition of painterly representation.

The painting presents a girl with red hair, her head in profile against a white pillow, sitting upright in what in fact was a big wicker chair. To her right sits a woman bowing her head, meant to represent a mother (in fact it was the child's aunt) mourning a dying child. The painting was overworked, unable to satisfy the demands of a popular genre, and met with little understanding from the general public. The typical genre clichés were lacking or not up to standards, while the required details of this popular genre form were blurred by an impasto paint that threatened to make the medium itself opaque. In these shortcomings we recognize a typical, and even necessary, condition of modern art. Munch himself considered the result unsatisfactory and reworked the painting a decade later. The conviction behind these revisions reflected a change from a naturalism that welcomed genre to symbolism with its generic and far more pretentious take on death. The original version of The Sick Child was in Munch's own words "heavy as lead," presumably with the exception of the child's red hair, while the revised right half of the painting was

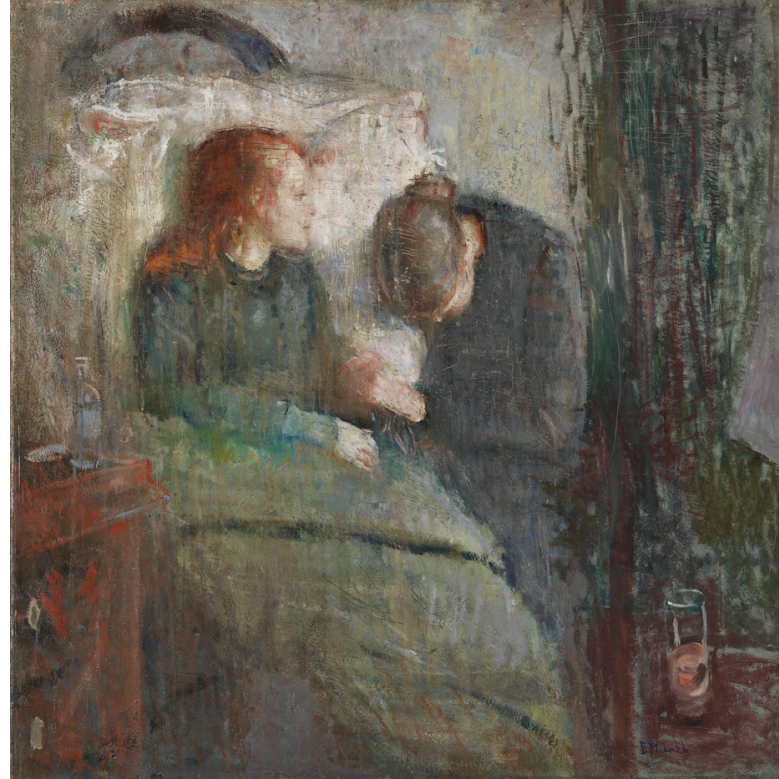

Figure 1. Munch, Edvard (1886) The Sick Child. Oil on canvas. The National Museum of Art, Architecture and Design. Oslo, Norway. Photo: Høstland, B. 
executed in fresh alla prima brushstrokes, mostly in red and dark green to rebuild the color contrast in the picture.

Well before today's postdisciplinary and postmedium situation in art, painting had to dissolve genre divisions if it was to count as being modern. By the turn of the last century, genre painting was becoming obsolete. The Sick Child was to be the painting that managed almost by itself to subvert the genre called genre painting when it was shown in 1886. Still, there was a twist in the effect it had on national art history. Something peculiar happened in the reception of this particular painting. It came to carry the truth of genre painting, as if all the pictures of children dying from tuberculosis at the time were given their reference to real life through Munch's break with genre painting. In retrospect, The Sick Child became the icon of the tuberculosis pandemic, historicizing genre painting by being the picture of the picture of tuberculosis, both a meta-picture and the referent, the effet $d u$ reel of all obsolete genre painting, "tæringsgenren" (the consumption genre).

After this single incident no painted picture of tuberculosis was to be about such an easily recognizable loss, notwithstanding that the illness was a continual presence in people's lives. Both the visual language itself and what it referred to were displaced, whether it be tuberculosis or, a few years later in Munch's life, the more elevated cases of neurasthenia or anxiety. Both were worthy modern ailments and almost already art. Make no mistake, modern art is as content-driven as traditional art was, once guided by genre demands on presentation and presentability, such as melodramatic identification, empathy and idyllic bliss. The preoccupation with formal issues in modern art rests on an expanding and therefore unclear content, almost too shy to be identified. After The Sick Child no motifs would be interpreted with sole reference to genre topics. Twenty years later, Munch's younger colleague Ludvig Karsten painted a coloristically studied painting entitled Tuberculosis (1907) almost in bad faith. It shows a singular figure, an elderly woman, standing against a wall, pressed from both sides by two fields of color. The coloration is interesting but not too harmonious, suggesting a figure fighting over the conditions of how she is to be presented in paint

\section{UNFORGIVEN}

"No white hats" was the terse comment passed by an old father to his far more enthusiastic son after watching Clint Eastwood's western masterpiece Unforgiven in a local cinema somewhere in Colorado in 1992. (Unforgiven is almost on par with another great Eastwood western, The Outlaw Josey Wales from 1976). The father's comment expresses the conviction that there is a price to pay for updating the western genre, and the price is not simply one of a better morale indicated by the cliché of the hero's white hat. His comment reveals outmoded preferences and a forlorn idealism. By insisting on the fiction, that is, the difference between the western genre and updated demands for cinematic realism, the father was defending the functionality and therefore the truth of genre. I would like to pay the old man his due. What impresses is his self-confidence and assurance, not to mention his ability to express this confidence in one striking expression.

Evidently, Eastwood did not want to give his hero away by the color of his hat. But the father, familiar with the traditional western, may have had something else in mind. He thought that Unforgiven was a movie with no clean-cut characters, 
much less clean motives, though the movie made use of a whole range of other recognizable genre clichés.It might be that Unforgiven is a better film than more typical examples of the genre, and therefore a successful case of genre innovation, or what might be called a sublated western. In any case, it is still undeniably a western. The point is rather that the father knew what he wanted, and the expectations he had for a full night's entertainment were correct beyond those of a customer. Moreover, he may have known something the producer had forgotten. Since the mythical time of the western is fixed, he was perceptive to problems the genre will meet when improved by updated mores.The father obviously found the genre type more entertaining than even the slightest revisionist take on it. This makes him a pessimist or rather a classicist of genre. Westerns with white hats expose the myth, while every western with "no white hats" still feed on the myth. The former has the vitality of a myth, while in Unforgiven the hero becomes a hero by his deeds and regrets, not by his looks - the traditional one-to-one relation between what you see and what you get. The complication of this simple one-to-one relation indicates problems concerning a surplus of fiction in the genre. Eastwood updates the western to meet new demands on realism, and westerns should be moderately realistic, while the reference to the hat is an idealism for grown-ups and for an older cinematic language. The old man does not want to swap day dreams for real nightmares, notwithstanding that you learn more from the latter if only because you deserve them. He prefers an obvious fiction because the western will forever be such stuff as dreams are made on.

\section{BLIND WILLIE MCTELL}

The third example concerns Bob Dylan's ambitions as a "song and dance man," as he once modestly called himself at a press conference early in his career in response to whether he considered himself to be a poet - as a lot of his fans did - or a singer. Modesty and mystification aside, he was an entertainer who wrote songs clearly asking to be read as well, and thus promoted an uncommon type of artist, a performing author. Albeit that the musical structure of his songs was based on rather anonymous genre music, which he electrified and gave a lasting personal imprint. Did Dylan manage to lend well-worn musical forms the dignity of poetry, or was he just another inauthentic entertainer simulating bygone folklore while displaying liter- ary presumptions way beyond the musical genres he chose? He may have fallen between stools when entertaining educated young adults with music that was text-based rather than merely complying with the social demands on a song and dance man. The happy outcome nobody expected was the invention of clichés for a "genre" known as Americana, of which Blind Willie McTell is a revealing example. Every line of this song's lyrics, every historical picture of America it presents, is a cliché. The musical structure is minor key blues, much like the klezmer introduction to W.C. Handy's St. Louis Blues, or the anonymous St. James Infirmary Blues, which Dylan cites obliquely in the last verse ("St. James Hotel"). Either way, it was to his advantage since the impact of any form of popular music speaks in favor of clichés. Nothing but clichés would do.

For years, a couple of days prior to the announcement of the Nobel laureate in literature, voices were raised declaring that Dylan should finally be awarded the prize - voices that finally found satisfaction in 2016. Yet this recognition of Dylan by the Swedish Academy presupposes the tacit inclusion of those who write for the ear and perform in song - that is, it takes for granted that the standard for written and sung poems are one and the same. Up until 2016, the Nobel Prize was awarded to writ- 
ten images, not live performances. Dylan writes songs that are literary without being mistaken for literature, music driven less by the songs' poetic content than by their literary form, which he nails down in unfailing rhymes and snappy expressions, conveyed with a timing and articulation no one is able to match, and adjusted to the genres he employs, which is to say almost every American genre of popular music including, in the last twenty years of his career, early swing jazz.

Blind Willie McTell was recorded in May 1983 with Dylan on piano and Mark Knopfler of Dire Straits on guitar, but the recording was first released when The Bootleg Series appeared almost a decade later. The famous single line refrain is strangely unrelated to the lyric's series of tableaux and never quite catches up with the rest of the song or wraps it up like a refrain should do: "No one can sing the blues like Blind Willie McTell.” McTell was a songster who performed ballads, gospel, and blues, and was as a remarkable twelve-string guitarist in his use of bottleneck and open tunings. Besides covering contemporary Tin Pan Alley hits for his local audience around Atlanta, Georgia, ballads, gospel, and blues were the three main genre options for a solo black entertainer during the early recordings of "race records" from the late 1920 s to the mid-1930s. Dylan's later recordings of McTell's songs include the murder ballad Delia and the twelve bar blues Broke Down Engine, both on the 1993 album World Gone Wrong on which he performs old songs he probably appreciated in his folk revivalist youth. Dylan has always recycled songs by others by equipping them with new or slightly improved lyrics and signing them anew, but McTell's was a signature too strong to erase. This poetic technique, with its partly denied form of imitation, was given a name with the title of Dylan's 2001 album Love and Theft. The title was stolen as well, this time from the music historian Eric Lott, who brought the case to court. As a thief in love with his contraband, Dylan is never boring or pedagogical. He is always an impersonator, taking the first singular person perspective on whatever song he performs, in contrast to folksinger Pete Seeger, who performs even his own songs in the position of an inclusive, big "we," as if the songs were written by others. Whatever Dylan loves strongly enough to steal, he performs as if he is speaking personally, intent on appearing as the originator of the song. When the song is old or worn, it takes a trick or two and a strong signature to appear in the position of the one who once wrote it.
Dylan was credited early on for being able to present complex issues in a simple and striking manner. He would adapt what was on his mind to slightly revised expressions from well-known genres like the ballad or the blues, and this sufficed to renew popular music in the 1960s. My question to a favorite entertainer, who just like McTell does so much more than simply entertain, concerns Dylan's ambitions as "a poet, and I know it/ Hope I don't blow it," as he says in one of his self-ironical rhymes. That is, does the homage to McTell risk becoming some kind of tourism in American history and a renewed, invisible form of the old blackface performance - a white performing as a black man to a white audience. As such, it would betray an inauthenticity Dylan fans are unwilling to accuse him of for the simple reason that the sources of his tourism, like McTell, would be inaccessible without a go-between and mediator like Dylan. The distance to the original recordings of local black performers in the 1920 s, revealed in the very category "race records," will never be bridged, so we indulge in the illusion Dylan presents and pardon him for his lack of genuine aesthetic judgment and disrespect for the distance to his sources. No doubt, Dylan writes better lyrics than McTell, "better" meaning not more effective but just more modern and more 
written. Dylan has no other choice than to make the leap, in Schiller's words, from naïve to sentimental, that is, to a more reflective poetry with its strong sense of loss and disturbing sense of cliché. Dylan goes on to gather dead voices from the musical archive, but in his subject position as an impersonator he still remains an archivist.

Following Dylan from his early retake on historical (local) pop music to contemporary rock music and then Americana - a genre Dylan is said to have invented and a recognizable as well as profitable industry - it still feels overstretched to call Americana a genre and the span of his musical career an "immanent" rhythmic development between genres.From a position opposite art, Dylan achieves something similar to what Munch managed to do to genre painting. Both remain somewhat too vernacular, too communicative, to count as a typical modern poet/painter. Their goal may have been a little short on sublimation, lacking a purified art in the end. Blind Willie McTell became generic Americana, just like The Sick Child became the generic genre painting ("tæringsgenren"), that is, a concept of a specific genre rather than an example of it. This was achieved precisely by an exit from genre and with a painting that was to stand out as an exception in Munch's oeuvre. Despite breaking with genre expectations and recognizable narrative details, the painting's content still matters. By taking the figure of a sick child from memory, Munch lost his firm grip on naturalist observation, but it is first in retrospect that this painterly loss became the actual loss of his sister. Dylan's Blind Willie McTell has the air of access to memory and the ground on which folk music moved, and this is inauthentic to say the least. Eastwood extends and accentuates the part of naturalism and the everyday in his last take on the western - a process that continues to this day to the detriment of the western genre. Still, an exit is kept open through the misery of the settler life, and the reason is that both the landscape and the historical period are stable and mythic. No hat is white anyway, when seen against the setting sun.

\section{CONCLUSION}

To conclude, genre weakens when it opens up and turns descriptive, and its form of sensitivity has to catch up. No extension of it, however, will take away its power to authorize a judgment or measure conformity to a standard. This power is challenged only when genre is brought too close to other typologies, like art, or to purely technological definitions of a particular medium. Secondly, there is something ungrammatical, maybe even an instrumental fallacy, in the ambition to create a genre. You make an artifact belonging to a genre, not a set of rules for a genre that subsumes a practice that doesn't yet exist. The strange characteristic of genre, where every revision when accepted shows the norms to be elastic and substantiated by the revision, points to differences of media technology. Successful revisions always turn out to be more inherent to the genre than the elements they replace. Maybe it is imitation more than anything else which, by inviting social complacency, comes closest to producing a new genre, though it runs the risk of being subsumed by a genre already in place. Thirdly, revisions never improve the patterns of the genre but change it involuntarily. It turns out that the pattern becomes definitive by what it excludes. Genre is not a scheme for improvement but rather the sum of total improvements. Fourth, and finally, the genre concept is reminiscent of classicist poetics with its shift of emphasis from producer to receiver: the consensus about norms for what is to be expected, 
where the anticipation of possibilities based on convention replace the test of experience. In genre resides the wit of orthodoxy. This is the opposite of the logic of Hegelian sublation, since sublation is what is commonly understood by criticism: to lift the artifact up to the concept, leaving it behind as an aesthetic fact.

Modern painting abandoned genre for art pure and simple, leaving genre to be a mere pretext for still recognizable forms in a period of transition (expressionism), a period whose return, it would seem, has no end. The exit was not final, opening up a life beyond genre in order to rescue painting from becoming obsolete when its communicative function was handed over to emerging repro-technical media like photography and film. With the western, living inside a new medium, genre survives any improvement. While fighting idealized irrelevance (white hats) or a surplus of fiction from within, no improvement can possibly change the mythic backdrop of the genre. Dylan's finally released Blind Willie McTell comments on genre music by affixing Dixie clichés to a blues ballad, which in itself is a transitional genre or genre mix. He not only recirculates a musical form but also insists on taking the position of the old songster by borrowing and representing his convictions, thereby casting the gaze of the dead on his contemporaries. This has contributed to his ability to renew himself and has given him a much-needed distance to the music industry of his own times. In this song a certain solemnity overtakes him, where he drops the theft for the love of his sources. For obvious reasons there will never be another McTell, though we may live to see a more perfect western that reinvents the settler ethos in the margins of Hollywood productions. The difference is not merely one of generic genre versus historical record. In the former art was an exit from genre, while the latter is undisturbed documentation. All genre extension turns to either of these - art or record, monument or document - when fiction becomes opaque and too intrusive.

\section{REFERENCES}

Derrida, Jacques. (1978). From restricted to general economy: a Hegelianism without reserve. In Jacques Derrida, Writing and Difference (pp. 251-277). Chicago: The University of Chicago Press.
Derrida, Jacques. (1992). The law of genre. In Jacques Derrida, Acts of Literature (pp. 221-252). London: Routledge.

Dylan, Bob. (1991/1983). Blind Willie McTell, The Bootleg Series, vol. 3, Columbia 02-488100-10.

Dylan, Bob. (1993). World Gone Wrong, Sony BMG, ASIN: Boo15RCUSW.

Eastwood, Clint (2002/1992). Unforgiven, 10th Anniversary, Two-Disc Special Edition, Warner Bros., Z12 23457.

Fried, Michael. (1998). Manet's modernism: Or, the face of painting in the 186os. Chicago: University of Chicago Press,

Hegel, Georg. (1976/1807). Phänomenologie des Geistes (Phenomenology of the spirit). Frankfurt am Main: Suhrkamp Verlag,.

Munch, Edvard. (1885-86). Det syke barn (The Sick Child), The National Museum Oslo, Collection number 839 .

Karsten, Ludvig. (1907). Tæring (Tuberculosis), The National Museum Oslo, Collection number 963. Store norske leksikon (1995). 2nd edit. "genremaleri", vol. 6, p. 76, "sjanger”. vol. 13 p. 253, Kunnskapsforlaget, Aschehoug \& Gyldendal, Oslo. 